\title{
Protestantism and the new science in Jan Amos Comenius' Via lucis Vitor Albiero*
}

\section{PhD Dissertation}

\section{Pontifical Catholic University of São Paulo, Brazil}

Unlike the researches on the pedagogical principles of Jan Amos Comenius (1592-1670), few studies have been produced about the author's involvement with the purpose and usefulness of the new science.

However, based on Via lucis, which Comenius wrote when he was in England invited by Samuel Hartlib (1600-1662), between 1641 and 1642, and which he dedicated to the Royal Society of London in 1668, the present study sought to assess the interrelationship between some assumptions of Protestantism and $17^{\text {th }}$ century natural philosophy.

The first chapter approaches the life and training of the author, as well as the cultural and religious sources to which he had resource in the construction of the theoretical basis of his conception of knowledge and his idea of universal knowledge (pansophical thought). These aspects were related to the social, cultural and religious conditions that contributed to the formation and performance of the so-called Hartlib group, which corresponded to the concerns of the English General Reformation. The second chapter discusses the relationship between theology and the new science in Via lucis, where Comenius' theological assumptions, which legitimized the Protestant participation in the development of the new philosophy are described. It highlights the concept of revelation (as knowledge) and its relationship to the construction of the new natural philosophy, in addition to approaching the biblical-theological principle of the Fall and the mitigating action of the new science on the deleterious effects of sin. The identification of the Comenian millennial eschatology related to efforts for the spread of knowledge and the advance of the new science is also discussed. The last chapter describes the relationship of the pan-harmony in Via lucis with the new science. Through the pan-harmonic system elaborated by Comenius, one might understand how the apprehension, organization and diffusion of universal knowledge was related to the establishment and advance of the new science. Pan-harmony is presented as a way to reach the Universal Reformation, and based on the pan-harmonic concept, examples of attempts by the author to cooperate with the method, organization, and production of the new science are provided. Finally, it is exposed the Comenian expectation that the Via lucis would aid the work of the Royal Society, as well as contribute with the efforts for the sake of Universal Reformation.

Seemingly, this seldom approached work by Comenius does not only concentrate his dream of Universal Reformation, but also the expectations aroused during his stay in London with the promoters of the new science. Such expectations also seem to reveal that both Protestantism and the new science yearned for universal knowledge, based on the investigation of nature, educational development, social apparatus and the advancement of a useful science.

Thus the present study hopes to contribute to the studies in history of science by proposing a salutary historiographical discussion based on the combination of the correlations between Protestantism and natural philosophy, patently present in the process and conceptualization of knowledge in $17^{\text {th }}$-century English science.

\section{Keywords}

History of science; Comenius; Protestantism; New science

\footnotetext{
${ }^{*} \bowtie$ vitor.albiero@ig.com.br
} 